\title{
Social Discounting and Incentive Compatible Fiscal Policy*
}

\author{
Catarina Reis ${ }^{\dagger}$ \\ March 15, 2009 - Preliminary and Incomplete
}

\begin{abstract}
This paper considers a Ramsey model of linear capital and labor income taxation in which the government cannot commit ex-ante to a sequence of policies for the future. In this setup, if the government is more impatient than the government, the capital income tax will always be positive in steady state. Thus, impatience and lack of commitment are able to generate positive capital taxes in the long run, although each of these characteristics individually was not. Furthermore, the steady state to which the economy converges is independent of initial conditions.
\end{abstract}

Keywords: Fiscal Policy, Optimal Taxation, Incidence, Debt

JEL Classification: E62, H21, H22, H63

\section{Introduction}

A long-standing question in public economics has been the extent to which capital taxes should be used to finance public spending. Seminal work by Chamley (1986) suggests that in an economy of infinitely lived identical agents, the optimal capital income tax asymptotes to zero in the long run.

In the absence of government commitment this result remains true as long as the government is allowed to borrow and lend from households, as shown by Dominguez (2007) and Reis (2007), but not if the government is forced to keep budget balance every period, as happens in Benhabib and Rustichini (1997) and Phelan and Stachetti (2001). Thus, the ability to accumulate assets over time is key to overcome the lack of commitment, since a wealthier government has a smaller incentive to default on its promises.

*I am grateful to Mike Golosov and seminar participants at the Econometric Society NAWM 2008 and Federal Reserve Board for helpful comments.

${ }^{\dagger}$ School of Economics and Management, Universidade Católica Portuguesa, email: creis@fcee.ucp.pt. 
However, all these papers assume that the government and households share the same exponential discount rate. De Bonis and Spataro (2005) analyze the effects of allowing this discount rate do differ, and find that if governments are more patient than households they will accumulate assets over time, and have capital subsidies that incentivize households to save according to the government's discount rate. On the other hand, if governments are more impatient than households, they will run deficits and increase their debt over time, but the capital tax still converges to zero in the long run. Thus, this model is still not able to generate positive capital taxation in the long run except for the very particular case where utility is logarithmisc in consumption.

This paper introduces a model where the government cannot commit, and also allows the government's discount rate to differ from that of the households. For the case where the government is more patient than the households, both forces go in the direction of leading the government to save, so the long run prediction do not differ from the model with full commitment. When the government is more impatient than households, however, the impatience leads the government to run deficits, whereas the lack of commitment gives an incentive to accumulate assets. The result is that the economy will converges to a point where the two effects exactly offset each other, and which is independent of initial conditions. In this steady state, capital taxes will be strictly positive as long as the difference between the two discount rates is positive.

Notice that despite the difference in discount rates, the government remains benevolent in the sense that it maximizes a weighted sum of each generation's instant utility. The weight put on each generation may differ from that of a representative household, either because a direct weight is put on future generations' utility, as in Farhi and Werning (2007), or because of paternalism or an informational advantage of the government.

An alternative interpretation would be to think that the government may exhibit higher impatience for political economy reasons, since it may stay in power for a limited period of time. In this sense, this paper is also related to the political economy literature that analyses the effect of government impatience on equilibrium policies, as in Acemoglu, Golosov, and Tsyvinski (2008). However, in that literature the government maximizes a weighted sum of his own rents, whereas in this paper the government maximizes a weighted sum of households' utility, albeit using a different discount rate from the households.

\section{The Economy}

This section introduces the economy, and characterizes the set of attainable allocations using a primal approach.

The economy has a continuum of measure one of infinitely lived identical households, an arbitrary number of firms that behave competitively, and a government. Time is discrete. The economy is identical to that of Reis (2007), but it introduces irreversibility of non-depreciated capital. 


\subsection{Households}

Households derive utility from consumption $c_{t}$, labor $n_{t}$, and consumption of a public good $g_{t}$. They discount the future at rate $\beta$, with $0<\beta<1$, so that each household's lifetime utility is given by

$$
\sum_{t=0}^{\infty} \beta^{t}\left[u\left(c_{t}, n_{t}\right)+v\left(g_{t}\right)\right] .
$$

Assume $u$ is increasing in consumption and decreasing in labor and globally concave. The usual Inada conditions hold $u_{c}(0, n)=-u_{n}(c, \infty)=\infty$ and $u_{n}(c, 0)=u_{c}(\infty, n)=$ 0 . Assume also that the utility of the public good $v$ is increasing and concave with $v^{\prime}(0)=\infty$ and $v^{\prime}(\infty)=0$.

For each unit of work, households receive after tax wages of $w_{t}\left(1-\tau_{t}^{n}\right)$. Households can transfer consumption between periods using capital $k_{t}$ or government bonds $b_{t}$. Households rent their capital $k_{t}$ to firms for which they receive an after tax return of $r_{t}\left(1-\tau_{t}^{k}\right)$. Capital depreciates at rate $d$, and the non depreciated capital is irreversible, so that $k_{t+1} \geq(1-d) k_{t}$. Irreversible capital cannot be taxed and the price of capital is $p_{t}$. Although the consumption good can be freely transformed into capital, the converse is not true, which means that the price of capital may be below one. All taxes have to be lower than one, but they are allowed to be negative. A bond that pays one unit of consumption good in period $t+1$ costs $q_{t}$ units of consumption good in period $t$. The government can choose to make lump sum transfers $T_{t}$ to the households, which must always be positive.

Thus, households must meet the following budget constraint every period, as well as a no-ponzi condition that guarantees that the value of their debt remains bounded. Since the marginal utility of consumption is always positive, we can assume, without loss of generality, that the budget constraint is always met with equality

$$
c_{t}+p_{t} k_{t+1}+q_{t} b_{t+1}=p_{t}(1-d) k_{t}+r_{t}\left(1-\tau_{t}^{k}\right) k_{t}+w_{t}\left(1-\tau_{t}^{n}\right) n_{t}+b_{t}+T_{t} .
$$

Households choose consumption, labor, and investment in capital and bonds to maximize the present value of utility subject to their budget constraints and no-ponzi condition for given $k_{0}$ and $b_{0}$. Given that utility is concave and the constraint set is convex, the following first order conditions, together with the households' budget constraints and no-ponzi condition, are necessary and sufficient for household optimality

$$
\begin{aligned}
u_{n}\left(c_{t}, n_{t}\right)+w_{t}\left(1-\tau_{t}^{n}\right) u_{c}\left(c_{t}, n_{t}\right) & =0 \\
q_{t} u_{c}\left(c_{t}, n_{t}\right)-\beta u_{c}\left(c_{t+1}, n_{t+1}\right) & =0 \\
u_{c}\left(c_{t}, n_{t}\right) p_{t}-\beta\left[(1-d) p_{t+1}+r_{t+1}\left(1-\tau_{t+1}^{k}\right)\right] u_{c}\left(c_{t+1}, n_{t+1}\right) & =0
\end{aligned}
$$

This fully characterizes the households' optimal response to a given path of policies and prices. 


\subsection{Government}

The government receives revenue from proportional taxes on labor $\tau_{t}^{n}$ and capital $\tau_{t}^{k}$ each period. It decides how much to buy of the public good $g_{t}$ every period and the amount of lump sum transfers to the households $T_{t} \geq 0$. It also needs to repay its debt $b_{t}$, and can lend or borrow from households. Given this, the government's per period budget constraint is given by

$$
g_{t}+T_{t}+b_{t}=w_{t} \tau_{t}^{n} n_{t}+r_{t} \tau_{t}^{k} k_{t}+q_{t} b_{t+1} .
$$

\section{$2.3 \quad$ Firms}

Each period, firms maximize profits given the prices for labor $w_{t}$ and capital $r_{t}$. They have access to the production function $F\left(k_{t}, n_{t}\right)$, which has constant returns to scale and is increasing and concave in both factors of production. Assume $F_{k}(0, n)=F_{n}(k, 0)=$ $\infty$, and $0 \leq F_{k}(\infty, n)<d$. Firm profits are thus given by

$$
\pi=F\left(k_{t}, n_{t}\right)-r_{t} k_{t}-w_{t} n_{t} .
$$

Firm optimality and market clearing imply that factor prices are given by the marginal productivity of each factor

$$
\begin{aligned}
w_{t} & =F_{n}\left(k_{t}, n_{t}\right) \\
r_{t} & =F_{k}\left(k_{t}, n_{t}\right) .
\end{aligned}
$$

Firm ownership is irrelevant since the constant returns to scale technology ensures that profits are zero.

\subsection{Market Clearing}

In the goods market, the following resource constraint must be met every period

$$
c_{t}+g_{t}+k_{t+1}=F\left(k_{t}, n_{t}\right) .
$$

Furthermore, due to the irreversibility of capital, the following conditions must also be met

$$
k_{t+1} \geq(1-d) k_{t}
$$

When the irreversibility condition is slack, increasing capital costs one unit of consumption good, so the price of capital must be one. On the other hand, when the condition bind the price of capital must be lower than one in order to increase the demand for capital, which means that the following conditions must be met

$$
\begin{aligned}
p_{t} & \leq 1 \\
\left(k_{t+1}-(1-d) k_{t}\right)\left(1-p_{t}\right) & =0 .
\end{aligned}
$$




\subsection{Attainable Allocations}

We now turn to finding the allocations that can be attained as the outcome of a competitive equilibrium in this economy.

Let $\pi=\left(\pi_{0}, \pi_{1}, \ldots\right)$ denote the sequence of government policies $\pi_{t}=\left(\tau_{t}^{n}, \tau_{t}^{k}, T_{t}, g_{t}\right)$, let $x=\left(x_{0}, x_{1}, \ldots\right)$ denote the sequence of household choices $x_{t}=\left(c_{t}, n_{t}, k_{t+1}, b_{t+1}\right)$, and let $\theta=\left(\theta_{0}, \theta_{1}, \ldots\right)$ denote the sequence of market clearing prices $\theta_{t}=\left(r_{t}, w_{t}, p_{t}, q_{t}\right)$.

A competitive equilibrium is a triplet $(\pi, x, \theta)$ that satisfies the following conditions: ( $i$ ) given $\pi$ and $\theta$, households choose $x$ to maximize utility subject to their budget constraints and no-ponzi condition; $(i i)$ the government meets its budget constraints and no-ponzi condition with $T_{t} \geq 0 ;($ iii) market clearing conditions are met.

This means that a triplet $(\pi, x, \theta)$ is a competitive equilibrium if it meets equations (1)-(4) with $T_{t} \geq 0$, equations (5)-(6), and equations (7)-(10), as well as a transversality conditions that ensures that the value of assets and debt remain bounded in the long run. We do not need to impose the government's budget constraint since it is always met when the remaining conditions are verified.

Following the approach developed by Lucas and Stokey (1983), we can simplify these conditions by multiplying the households's budget constraint by the marginal utility of consumption and plugging in the households's optimality conditions to get the following implementability condition

$$
\begin{gathered}
u_{n, t} n_{t}+u_{c, t} c_{t}+\beta u_{c, t+1} b_{t+1}+ \\
\beta u_{c, t+1}\left[(1-d) p_{t+1}+r_{t+1}\left(1-\tau_{t+1}\right)\right] k_{t+1}
\end{gathered}=\begin{gathered}
u_{c, t} T_{t}+\beta u_{c, t} b_{t}+ \\
u_{c, t}\left[(1-d) p_{t}+r_{t}\left(1-\tau_{t}\right)\right] k_{t} .
\end{gathered}
$$

Define $m\left(c_{t}, n_{t}\right) \equiv u_{c}\left(c_{t}, n_{t}\right) c_{t}+u_{n}\left(c_{t}, n_{t}\right) n_{t}$ and make a change of variables to replace the value of consumer assets $a_{t} \equiv u_{c}\left(c_{t}, n_{t}\right)\left[(1-d) p_{t}+r_{t}\left(1-\tau_{t}\right)\right] k_{t}+u_{c}\left(c_{t}, n_{t}\right) b_{t}$ for nominal bonds $b_{t}$ to write the implementability condition as

$$
m\left(c_{t}, n_{t}\right)+\beta a_{t+1}=u_{c}\left(c_{t}, n_{t}\right) T_{t}+a_{t} .
$$

Let $y=\left(y_{0}, y_{1}, \ldots\right)$ denote the sequence of allocations $y_{t}=\left(c_{t}, g_{t}, n_{t}, k_{t}, a_{t}\right)$. An allocation $y$ is attainable if there are prices and policies such that it will be the outcome of a competitive equilibrium for a given initial level of capital and government debt.

Lemma 1 An allocation $y$ is attainable if and only if it meets the following conditions for $t \geq 0$

$$
\begin{aligned}
m\left(c_{t}, n_{t}\right)+\beta a_{t+1} & \geq a_{t} \\
k_{t+1} & \geq(1-d) k_{t} \\
c_{t}+g_{t}+k_{t+1} & =F\left(k_{t}, n_{t}\right),
\end{aligned}
$$

with $\lim _{t \rightarrow \infty} \beta^{t} a_{t+1}=0$ and given $k_{0}$ and $a_{0} \geq u_{c}\left(c_{0}, n_{0}\right) \min \left(0, b_{0}\right)$. 
Any attainable allocation can be implemented using the following taxes

$$
\begin{aligned}
\tau_{t+1}^{k} & =1-\frac{1}{F_{k, t+1}} \frac{p_{t} u_{c, t}}{\beta u_{c, t+1}}+\frac{(1-d) p_{t+1}}{F_{k, t+1}} \\
\tau_{t}^{n} & =1+\frac{1}{F_{n, t}} \frac{u_{n, t}}{u_{c, t}}
\end{aligned}
$$

with the price of capital given by

$$
p_{t}= \begin{cases}1 & \text { if } k_{t+1}>(1-d) k_{t} \\ (1-d) p_{t+1} \beta u_{c, t+1} / u_{c, t} & \text { if } k_{t+1}=(1-d) k_{t}\end{cases}
$$

This characterization of attainable allocations will be useful to determine the optimal policies in the next sections.

\section{Optimal Taxes with Commitment}

This section introduces the benevolent government whose discount rate is given by $\delta$, which is allowed to be different from the households's discount rate $\beta$. It sets up the government's problem and introduces a recursive formulation of the problem to derive the De Bonis and Spataro (2005) results in our setting. A special case of this setup occurs when the two discount rates coincide, which gives us the benchmark Chamley (1986) result of zero capital taxes in the long run.

The Ramsey problem chooses among all the allocations attainable under commitment, the one that maximizes the welfare of the benevolent government. The outcome of a Ramsey equilibrium is a sequence $y$ that maximizes the present value of utility $\sum_{t=0}^{\infty} \delta^{t}\left[u\left(c_{t}, n_{t}\right)+v\left(g_{t}\right)\right]$ subject to $y$ being attainable and given an initial stock of capital $k_{0}>0$ and an initial level of debt $b_{0}$. In the initial period it is always optimal to choose $\tau_{0}^{k}=1$, since this loosens the incentive compatibility constraint. Given this, we can write the Ramsey problem using the following sequence formulation

$$
\begin{array}{cl}
\max _{y} & \sum_{t=0}^{\infty} \delta^{t}\left[u\left(c_{t}, n_{t}\right)+v\left(g_{t}\right)\right] \\
\text { subject to } & m\left(c_{t}, n_{t}\right)+\beta a_{t+1} \geq a_{t} \\
& k_{t+1} \geq(1-d) k_{t} \\
& c_{t}+g_{t}+k_{t+1}=F\left(k_{t}, n_{t}\right)+(1-d) k_{t} \\
& a_{0}=u_{c}\left(c_{0}, n_{0}\right) b_{0} .
\end{array}
$$

Using $a$ and $k$ as state variables this problem can be written recursively in the following way for $t>0$ 


$$
\begin{aligned}
\qquad(k, a)= & \max _{y}\left[u(c, n)+v(g)+\delta V\left(k^{\prime}, a^{\prime}\right)\right] \\
\text { subject to } \quad & m(c, n)+\beta a^{\prime} \geq a \\
& k^{\prime} \geq(1-d) k \\
& c+g+k^{\prime} \leq F(k, n)+(1-d) k .
\end{aligned}
$$

For the initial period, the problem is identical, but the implementability condition is given by $m(c, n)+\beta a^{\prime} \geq u_{c}(c, n) b_{0}$.

For the remaining of this section, assume that $m(c, n)$ is increasing in consumption, decreasing in labor, and globally concave, so that the constraint set is convex, and the value function $V(k, a)$ is concave, which guarantees that the first order conditions are necessary and sufficient for optimality.

Using $\mu$ as the multiplier on the implementability condition, $\chi$ as the multiplier on the irreversibility condition, and $\rho$ as the multiplier on the resource constraint we can write the Lagrangean for this problem in the following way

$L=u(c, n)+v(g)+\delta V\left(k^{\prime}, a^{\prime}\right)+\mu\left[m(c, n)+\beta a^{\prime}-a\right]-(\rho-\chi)\left[k^{\prime}-k+d k\right]-\rho[c+g-F(k, n)]$.

Combining the first order condition for $a^{\prime}$ with the envelope conditions for $a$, we reach the following equation

$$
\mu^{\prime}=\frac{\beta}{\delta} \mu
$$

Thus, if $\beta<\delta$, the government is more patient than households and the multiplier on the implementability condition $\mu$ converges to zero, which means that the government is accumulating assets over time, and does not need to use distortive taxation in the long run. On the other hand, if $\beta>\delta$, then the multiplier on the implementability condition $\mu$ converges to infinity, which means that the government is accumulating debt over time.

The first order condition for consumption is given by

$$
\rho=u_{c}+\mu m_{c}
$$

and when the irreversibility condition is not binding the first order condition for $k^{\prime}$ with the envelope conditions for $k$ lead to the following equation

$$
\rho^{\prime} \delta\left[1-d+F_{k}^{\prime}\right]=\rho .
$$

For the case when $\beta<\delta$, in a steady state with constant consumption, $\rho$ converges to the marginal utility of consumption, and the optimality condition for capital accumulation becomes $\delta\left[F_{k}+1-d\right]=1$, which means that capital must be subsidized since the optimal tax rate is negative and given by

$$
\tau_{t+1}^{k}=1-\frac{1 / \beta-1+d}{1 / \delta-1+d}<0 .
$$


On the other hand, if $\beta<\delta$, then $\rho$ converges to infinity (unless $m_{c}=0$, as in the logarithmic utility function) and grows at the same rate as $\mu$ in the long run, which implies that the optimality condition for capital accumulation becomes $\beta\left[F_{k}+1-d\right]=$ 1. Thus, in this case capital taxes converge to zero in the long run.

A special case of this model occurs when $\beta=\delta$, and the government has the exact same preferences as the representative household. In this case, $\mu$ is constant over time, and $\rho$ converges, but since the two discount rates have the exact same value, the optimal capital tax is zero, as in the benchmark Chamley (1986) result.

\section{Optimal Taxes without Commitment}

This section introduces lack of commitment to future policies, which means that the government is allowed to reoptimize its choices in every period. Thus, we will focus on a subgame perfect equilibrium where an incentive compatible policy path is enforced though a threat of reversion to a worst equilibrium which works as a punishment in the spirit of Abreu (1988).

\subsection{Worst Equilibrium}

Consider a policy path where households expect the government to always tax capital at $\tau^{k}=1$, and there is generalized default on bonds. If this is the case, the value of capital $p_{t}$ is zero and households never make new investment in capital or in bonds. The highest welfare the government can achieve under these circumstances is the solution to the following problem

$$
\begin{aligned}
\qquad V^{w}(k)= & \max _{c, n, g}\left[u(c, n)+v(g)+\delta V^{w}((1-d) k)\right] \\
\text { subject to } \quad & m(c, n) \geq 0 \\
& c+g=F(k, n)+(1-d) k .
\end{aligned}
$$

The value of this equilibrium only depends on the initial level of capital, and it is the lowest that can be achieved as a competitive equilibrium when the government is reoptimizing its policy in every period. For a complete discussion on the determination of worst equilibria in this setting, see Reis (2008) and Chari and Kehoe (1990).

Because households expect the government to fully tax capital, they never invest in capital, which means that the capital stock converges to zero over time as it depreciates. On the other hand, the government actually finds it incentive compatible to tax capital since it allows it to collect non distortionary revenue. Thus, the economy is stuck in a bad equilibrium where there is no investment, even though it would be extremely productive. This is where the assumption of capital irreversibility has the most impact in the model, since without it the capital stock would go to zero immediately. 


\subsection{Best Equilibrium}

In order to find the best competitive equilibrium that can be achieved in the absence of commitment, we have to maximize welfare subject not only to attainability, but also subject to an incentive compatibility condition that ensures that the government does not want to deviate from the chosen plan at any point in time.

To ensure that the solution we find is indeed the best equilibrium, it is necessary to make sure that the incentive compatibility condition is a loose as possible, which is achieved by using a threat to revert to the worst possible equilibrium, which was determined in the previous section.

Thus, the incentive compatibility condition is given by

$$
V\left(k^{\prime}, a^{\prime}\right) \geq V^{w}\left(k^{\prime}\right)
$$

and the best equilibrium is the solution to the following recursive problem

$$
\begin{aligned}
V(k, a)= & \max _{y}\left[u(c, n)+v(g)+\delta V\left(k^{\prime}, a^{\prime}\right)\right] \\
\text { subject to } \quad & m(c, n)+\beta a^{\prime} \geq a \\
& k^{\prime} \geq(1-d) k \\
& c+g+k^{\prime}=F(k, n)+(1-d) k \\
& V\left(k^{\prime}, a^{\prime}\right) \geq V^{w}\left(k^{\prime}\right) .
\end{aligned}
$$

As before, for the initial period, the implementability condition is given by $m(c, n)+$ $\beta a^{\prime} \geq u_{c}(c, n) \min \left(0, b_{0}\right)$.

This problem is well defined when the promised value of $a$ can credibly be repaid by the government, so that $a \leq \bar{a}(k)$, where $\bar{a}(k)$ is the value of household assets that makes the government indifferent between following the predefined plan and defaulting, so that $V(k, \bar{a}(k))=V^{w}(k)$.

Define also the first best welfare as the utility level that can be attained when the government does not need to use distortionary taxation, and which is the solution to the following recursive problem

$$
\begin{aligned}
\qquad V^{f b}(k)= & \max _{c, n, g, k^{\prime}}\left[u(c, n)+v(g)+\delta V^{f b}\left(k^{\prime}\right)\right] \\
\text { subject to } \quad & c+g+k^{\prime}=F(k, n) \\
& k^{\prime} \geq(1-d) k .
\end{aligned}
$$

Define $\underline{a}(k)$ as the highest value of consumer assets for which $V^{f b}(k)$ is attainable, so that $\underline{a}(k)=\max a$ st $V(k, a)=V^{f b}(k)$. Since $V(k, a)$ is a decreasing function of $a$, the fact that $V^{f b}(k)>V^{w}(k)$ implies that $\underline{a}(k)<\bar{a}(k)$.

Assume that the initial value of $a_{0}$ and $k_{0}>0$. are such that $\underline{a}\left(k_{0}\right)<a_{0}<\bar{a}\left(k_{0}\right)$. 


\subsection{Optimal Solution}

As in the full commitment solution, we will use a first order approach to find the solution to this problem. Since the problem may not be concave, the first order conditions are still necessary, but may not be sufficient for an optimum.

Associating the implementability condition with the multiplier $\mu$, the irreversibility condition with the multiplier $\chi$, the resource constraint with the multiplier $\rho$, and the government's incentive compatibility condition with multiplier $\gamma$, we can write the following Lagrangian for this problem

$$
\begin{aligned}
L= & u(c, n)+v(g)+\delta V\left(k^{\prime}, a^{\prime}\right)+\mu\left[m(c, n)+\beta a^{\prime}-a\right]+\chi\left[k^{\prime}-(1-d) k\right] \\
& -\rho\left[c+g+k^{\prime}-(1-d) k-F(k, n)\right]+\gamma\left[V\left(k^{\prime}, a^{\prime}\right)-V^{w}\left(k^{\prime}\right)\right] .
\end{aligned}
$$

Combining the first order condition for $a^{\prime}$ with the envelope condition for $a$, we reach the following equation

$$
\mu^{\prime}=\frac{\beta}{\delta+\gamma} \mu
$$

If $\beta<\delta$, the government is more patient than households and the multiplier on the implementability condition $\mu$ still converges to zero, as in the case with full commitment, since $\gamma \geq 0$. In this case, the government is still accumulating assets over time, and does not need to use distortive taxation in the long run. Thus, both $\gamma$ and $\mu$ converge to zero in the long run, which implies that the steady state the economy will converge to is the same as with full commitment, which has zero labor taxes and positive capital subsidies.

On the other hand, if $\beta>\delta$, the government is more impatient than households, and the multiplier $\mu$ may increase or decrease over time, depending on whether $\beta$ is higher or lower than $\delta+\gamma$. If $\beta>\delta+\gamma$, then $\mu$ is increasing over time, which means the government is increasing its debt, which in turn increases $\gamma$ until $\beta=\delta+\gamma$. On the other hand, if $\beta<\delta+\gamma$, then $\mu$ is decreasing over time, which means the government is reducing its debt, which in turn decreases $\gamma$ until $\beta=\delta+\gamma$. Thus, in the long run we must have $\gamma=\beta-\delta>0$. This means that in this case the incentive compatibility constraint remains binding in the long run, unlike the case where the two discount rates coincided. Furthermore, the multiplier $\mu$ is positive, constant, and bounded in the long run.

Proposition 1 (Positive capital taxes in steady state) In steady state, the best equilibrium has positive capital taxes.

Proof. Consider a steady state with constant $c, n, g, k$, and $a$. The first order condition for consumption is given by $\rho=u_{c}+\mu m_{c}$, which implies that $\rho$ converges to a positive value.

Since the irreversibility condition is not binding in steady state, the first order condition for $k^{\prime}$ with the envelope condition for $k$ imply that the following equation must be met

$$
(\gamma+\delta) \rho\left(1-d+F_{k}\right)=\rho+\gamma V^{\prime}(k)
$$


Since $\beta=\delta+\gamma$, this can be written as

$$
\beta\left(1-d+F_{k}\right)=1+V^{\prime}(k) \gamma / \rho>1 .
$$

Since the optimal capital taxes must satisfy the following equation

$$
\beta\left[1-d+F_{k}\left(1-\tau^{k}\right)\right]=1
$$

capital taxes will be strictly positive in steady state and given by

$$
\tau^{k}=1-\frac{1 / \beta-1+d}{1 / \beta-1+\delta+V^{\prime}(k) \gamma / \beta \rho}>0 \text { since } \frac{V^{\prime}(k) \gamma}{\beta \rho}>0 .
$$

Thus, when the government is more impatient than households, the incentive compatibility condition is always binding in steady state and, furthermore, capital taxes are always positive. Notice that this conclusion is different from other models where the incentive compatibility remains binding because the government is not allowed to save such as Benhabib and Rustichini (1997) and Phelan and Stachetti (2001). In those models, the lack of commitment was binding in steady state, but capital could either be taxed or subsidized depending on whether increasing capital loosened the incentive compatibility condition or not. Here, on the other hand, the optimal capital tax is always binding as long as the value of the worst equilibrium is increasing in the initial level of capital.

Proposition 2 (Positive labor taxes in steady state) In steady state, the best equilibrium has positive labor taxes.

Proof. Consider for simplicity the case where utility is separable in consumption and labor. The first order conditions for consumption and labor are

$$
\begin{aligned}
u_{c}(c, n)+\mu m_{c}(c, n) & =\rho \\
u_{n}(c, n)+\mu m_{n}(c, n) & =-\rho F_{n}(k, n) .
\end{aligned}
$$

The labor tax is given by

$$
\tau^{n}=1+\frac{1}{F_{n}} \frac{u_{n}}{u_{c}}=1-\frac{1+\mu m_{c} / u_{c}}{1+\mu m_{n} / u_{n}}=\mu \frac{m_{n} / u_{n}-m_{c} / u_{c}}{1+\mu m_{n} / u_{n}} .
$$

Since both $\mu$ and the denominator are positive, the labor tax will have the same sign as the numerator, which is given by

$$
\frac{m_{n}}{u_{n}}-\frac{m_{c}}{u_{c}}=\frac{u_{n n} n+u_{n}}{u_{n}}-\frac{u_{c c} c+u_{c}}{u_{c}}=\frac{u_{n n}}{u_{n}} n-\frac{u_{c c}}{u_{c}} c>0,
$$

since $u_{c}$ is positive and $u_{n}, u_{n n}$, and $u_{c c}$ are negative.

Thus, the labor tax is always positive as long as the multiplier on the implementability condition $\mu$ is positive, as happens in this case. 


\subsection{Characterization of Steady State}

A steady state for the economy where the government is more impatient than households is characterized by an allocation $y$ and multipliers $\mu$ and $\rho$ such that the following conditions are met

$$
\begin{aligned}
& u_{n}+\mu m_{n}=-\rho F_{n} \\
& u_{c}+\mu m_{c}=\rho \\
& v^{\prime}(g)=\rho \\
& c+g+k=F(k, n) \\
& m(c, n)=a(1-\beta) \\
& \beta\left(1-d+F_{k}\right)=1+V^{\prime}(k)(\beta-\delta) / \rho \\
& u(c, n)+v(g)=(1-\beta) V^{d}(k) .
\end{aligned}
$$

Since we have seven linearly independent conditions to determine seven variables, these equations will be able to pin down the steady state, which is independent of initial conditions. This allocation can be implemented as a competitive equilibrium using positive capital and labor taxes.

The following table summarizes how different assumption about commitment and discount rates affect the prediction for the steady state in a Ramsey model. The results on the column on the left are due to Chamley (1986), for the case where $\delta=\beta$ and to De Bonis and Spataro (2005) when $\delta \neq \beta$. For the column on the right, the result for $\delta=\beta$ was put forth by Dominguez (2007) and Reis (2007), whereas the contribution of this paper extends this analysis for the case where $\delta \neq \beta$.

\begin{tabular}{|c|c|c|}
\hline & With Commitment & Without Commitment \\
\hline \multirow{3}{*}{$\delta<\beta$} & capital tax $=0$ & capital tax $>0$ \\
& labor tax $=\max$ & labor tax $>0$ \\
& $\mathrm{~b}=$ debt limit & debt lim $<\mathrm{b}<$ asset lim \\
\hline \multirow{3}{*}{$\delta=\beta$} & capital tax $=0$ & capital tax $=0$ \\
& labor tax $>0$ & labor tax $>0$ \\
& b depends initial cond & b depends initial cond \\
\hline \multirow{3}{*}{$\delta>\beta$} & capital tax $<0$ & capital tax $<0$ \\
& labor tax $=0$ & labor tax $=0$ \\
& b $=$ asset limit & $\mathrm{b}=$ asset limit \\
\hline
\end{tabular}

The case where there is no commitment and $\delta<\beta$ seems of particular interest since its results replicate a lot of the observations of real economies, where both capital and labor taxes are positive, and governments accumulate debt which seems to remain stable after some time. 


\section{$5 \quad$ Numerical Simulations}

To illustrate the results of the model, consider an economy with preferences given by

$$
u(c, n)+v(g)=\ln (c)-0.5 \frac{n^{1.5}}{1.5}+0.8 \ln (g)
$$

and production function

$$
F(k, n)=2 k^{0.3} n^{0.7} \quad \text { with } \quad d=0.04 .
$$

The households' discount rate is $\beta=0.9$, and the government's discount rate varies between 0.8 and 0.9 .

Figure I shows how varying the government's discount rate affects steady state variables in the economy. As the government becomes more impatient (lower $\delta$ ), the steady state level of capital and output decreases, and the level od debt increases. Capital taxes also increase as the government becomes more impatient. Capital taxes approach zero as the government's discount rate approaches the households' discount rate $\beta=0.9$.
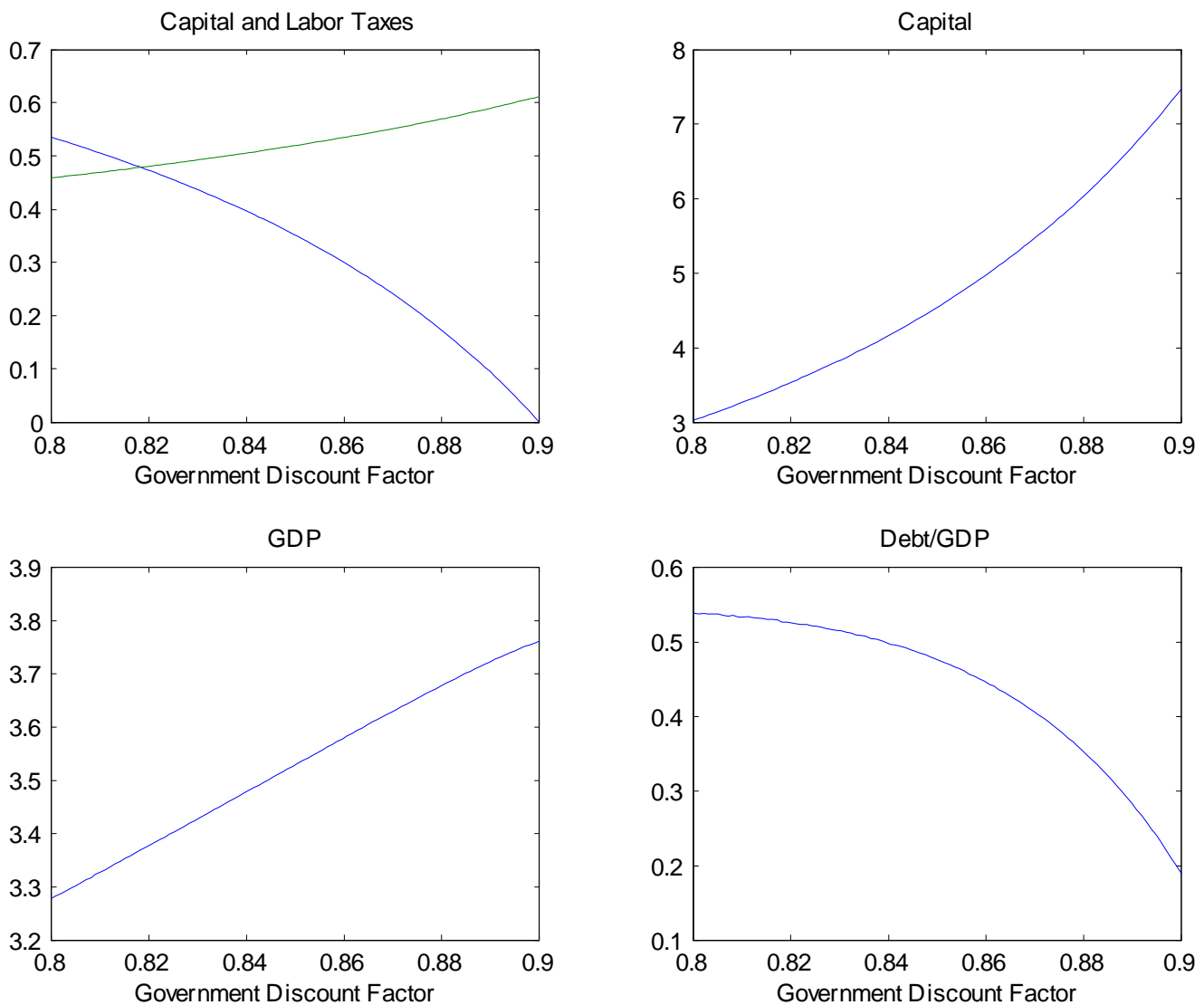

Figure I - Steady State for Different Government Discount Rates 
Figure II analyses the steady states in the economy when the government has the exact same discount rate as the households. Different levels of capital may be sustained in steady state, depending on how indebted the government is. A higher capital level is sustained when the value of consumer assets is low (which means that government debt is low) since this requires less distortive taxation The green line represents the value of the worst equilibrium, so only steady states where the blue line is above the green line are incentive compatible.
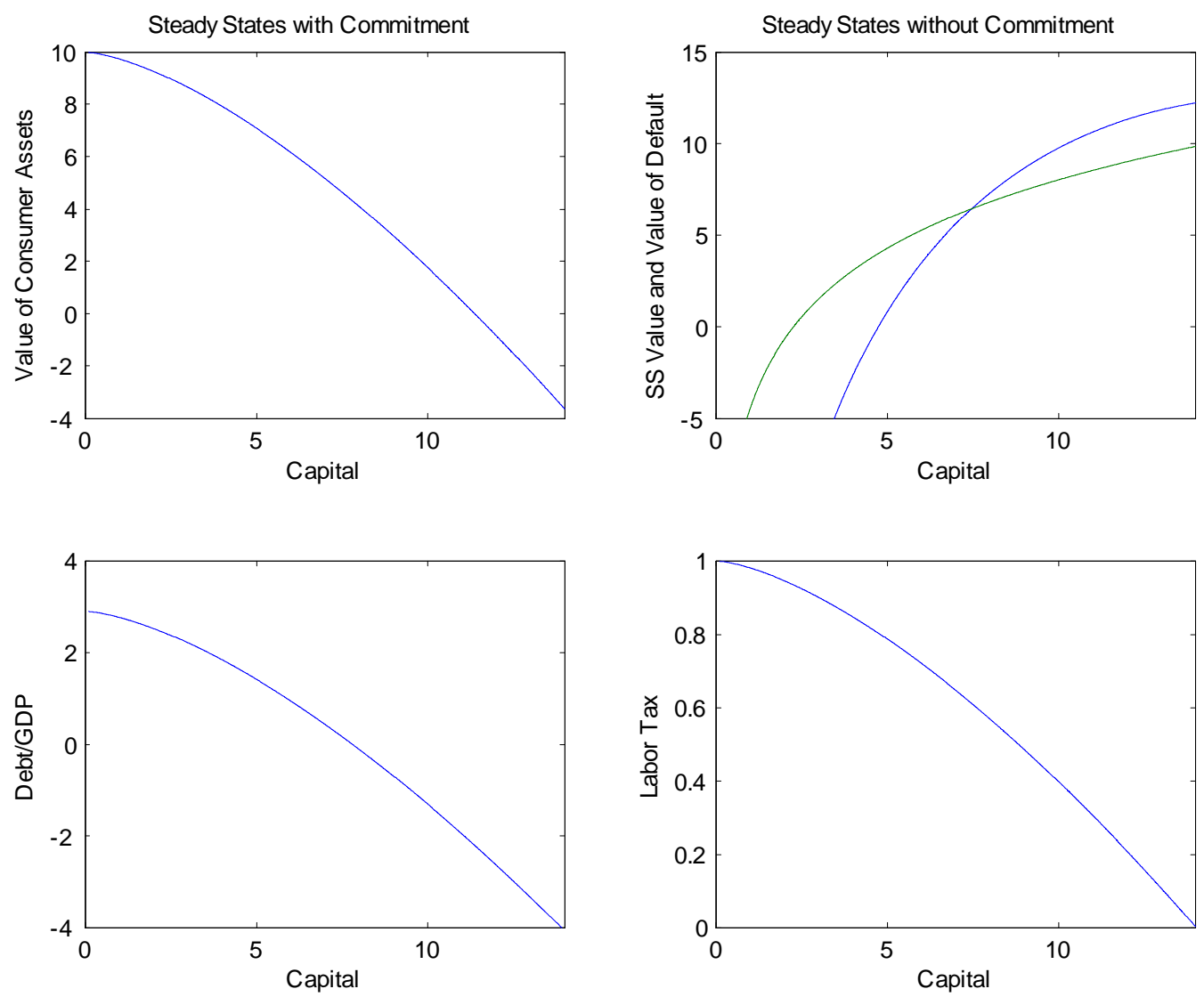

Figure II - Steady States when $\beta=\delta$ with and without Commitmnet

When the government's discount rate is below $\beta$, but is very close to $\beta$, the economy will be exactly in the point where the blue and green line intersect in figure II, which is also the point in figure I where $\delta=\beta$. Here, capital taxes are still approximately zero, but there is uniqueness in steady state equilibrium since the government will accumulate debt as long as the incentive compatibility condition remains loose. 


\section{Concluding Remarks}

This paper shows that by joining lack of commitment with government impatience, we are able to generate positive capital taxes in the long run in a Ramsey model of optimal taxation. This happens because the impatient government wants to correct the difference in discount rates by taxing capital in order to reduce capital accumulation, and the lack of commitment prevents government debt from growing too much, which would make it impossible to use capital taxation since labor taxes are able to collect the same revenue more efficiently.

Thus, the observation that in reality there is positive capital taxation together with bounded debt accumulation may be explained by a mix of lack of commitment and government impatience.

\section{References}

[1] Abreu, Dilip (1988) "On the Theory of Infinitely Repeated Games with Discounting," Econometrica, 56, 383-397.

[2] Acemoglu, Daron, Michael Golosov, and Aleh Tsyvinski "Political Economy of Ramsey Taxation," working paper.

[3] Benhabib, Jess and Aldo Rustichini (1997) "Optimal Taxes without Commitment," Journal of Economic Theory, 77, 231-259.

[4] Chamley, Christophe (1986) "Optimal Taxation of Capital Income in General Equilibrium with Infinite Lives," Econometrica, 54, 607-622.

[5] Chari, V.V. and Patrick Kehoe (1990) "Sustainable Plans," The Journal of Political Economy, 98, 783-802.

[6] De Bonis, Valeria and Luca Spataro (2005) "Taxing Capital Income as a Pigouvian Correction: The Role of Discounting the Future," Macroeconomic Dynamics, 9, 469-477.

[7] Dominguez, Begoña (2007) "Public Debt and Optimal Taxes without Commitment," Journal of Economic Theory, 135, 159-170.

[8] Farhi, Emmanuel and Ivan Werning (2007) "Inequality and Social Discounting," Journal of Political Economy, 115(3).

[9] Lucas, Robert, Jr. and Nancy Stokey (1983) "Optimal Fiscal and Monetary Policy in an Economy without Capital" Journal of Monetary Economics, 12, 55-93.

[10] Phelan, Christopher and Ennio Stacchetti (2001) "Sequential Equilibria in a Ramsey Tax Model," Econometrica, 69, 1491-1518.

[11] Reis, Catarina (2007) "Taxation without Commitment," working paper. 